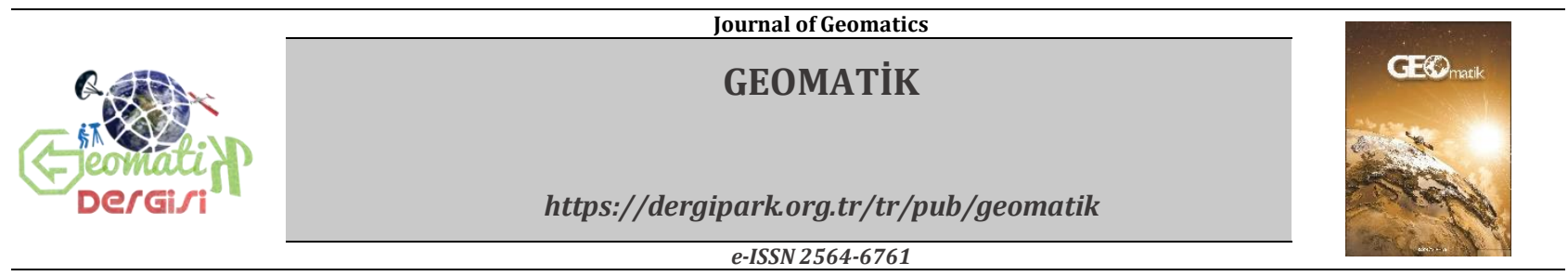

\title{
Arazi Toplulaştırması Dağıtım İşleminde Tek Amaçlı Genetik Algoritmanın Kullanılması
}

\author{
Hüseyin Eroğlu*, Yasemin Şişman \\ Ondokuz Mayıs Üniversitesi, Mühendislik Fakültesi, Harita Mühendisliği Bölümü, Samsun, Türkiye
}

\author{
Anahtar Kelimeler \\ Arazi Toplulaştırma \\ Genetik Algoritma \\ Optimizasyon
}

\begin{abstract}
ÖZ
Arazi toplulaştırması projelerinin başarısını doğrudan etkileyen en önemli adım olan blok dağıtımında birçok faktörün dikkate alınması gerekmektedir. Blok dağıtımı karmaşık, uzun zaman alan işlemdir ve büyük ölçüde dağıtımı yapan kişinin bilgi ve tecrübesine bağlıdır. Bu sorunlar dağıtım işlemi için yeni yöntemler geliștirilmesi ihtiyacını ortaya çıkarmıştır. Bu yüzden blok dağıtımı için yöneylem araştırma teknikleri, blok öncelikli model, mekânsal karar destek sistemleri, genetik algoritma ve hibrit dağıtım yöntemleri geliştirilmeye çalıșılmıștır. Bu çalışmada; dağıtım işlemi için önemli bir sorun olan blok dengelemesi ihtiyacını ortadan kaldıran bir dağıtım yöntemi önerilmiștir. Dağıtım, dengeli ulaştırma problemi olarak ele alınmış ve tek amaçlı genetik algoritma kullanılarak gerçekleştirilmiştir. Bu yöntemde blok dengelemesi problemine odaklanılmıştır. Bu yüzden dağıtım tek bir amaç fonksiyonuna göre yapılmıştır. Çalışmada Burdur Gölhisar Arazi Toplulaștırma Projesi Evciler köyü verileri kullanılmıştır. $\mathrm{Bu}$ yönteme göre yapılan uygulama sonuçları ile proje sonuçları karşılaștırılmıştır. Uygulama sonucunda bloklarda eksiklik ya da fazlalık oluşmamıştır ve blok dengelemesi yapılmamıștır. Sonuç olarak genetik algoritma yönteminde toplulaştırma oranı \% 27'den \% 41'e yükselmiștir.
\end{abstract}

\section{Using Single-objective Genetic Algorithm for Land Consolidation Distribution Process}

\author{
Keywords \\ Land Consolidation \\ Genetic Algorithm \\ Optimization
}

\begin{abstract}
Many factors must be considered in block distribution, which is the most important step that directly affects on the success of land consolidation projects. Block distribution is a complex, long time-consuming process and largely depends on the knowledge and experience of the person who do the block distribution. These problems revealed the need to develop new methods for the distribution process. Therefore, operations research techniques, block priority model, spatial decision support systems, genetic algorithm and hybrid distribution methods were tried to be developed for block distribution. In this study; a distribution method that eliminates the need for block balancing, which is a major problem for the distribution process, was proposed. Distribution was considered as a balanced transportation problem and it was performed using a single objective genetic algorithm. In addition, this method focuses on the problem of block balancing. Therefore, the distribution was made according to a single objective function. Evciler village data of Burdur Gölhisar Land Consolidation Project were used in the study. The results of the new application made according to this method and the original project were compared. It is seen that, there was no deficiency or overage in the blocks and no block balancing was made. As a result, the consolidation rate has increased from $27 \%$ to $41 \%$ using Genetic Algorithm method.
\end{abstract}




\section{GíRiş}

Dünya nüfusundaki artıș kıt kaynak olan tarım arazilerinin sürdürülebilir bir şekilde kullanımının önemini her geçen gün daha da arttırmaktadır. Yaşanılan iklim değişiklikleri, erozyon, çölleşme vb. ektilerden dolayı tarım arazileri üzerindeki baskı giderek artmaktadır (Göçmen Dinçbilek, 2012).

Artan dünya nüfusunun ihtiyaçlarını karşılayabilmek adına sınırlı miktardaki tarım arazilerinin daha etkin şekilde kullanılabilmesi için birtakım önlemler alınması gerekir. Arazi toplulaştırması da bu önlemlerden bir tanesidir. Ayrıca arazi toplulaştırması sayesinde parçalanmış, şekilsiz tarım arazileri tarımsal mekanizasyona uygun şekle getirilir. Böylece toplulaştırma sonrası, parsellere ulaşımda ve şekilsiz parselleri işlerken harcanandan daha az yakıt harcanacak buna bağlı olarak karbon salınımı azaltılarak doğaya daha az zarar verilecektir (Polat \& Manavbaşı, 2012).

Arazi toplulaştırması birden fazla amacın birlikte değerlendirilmesini gerektiren karmaşık, uzun zaman alan süreçtir. Blok dağıtımı arazi toplulaştırmasının en hassas aşamasıdır. İyi yapılmış bir blok dağıtımı arazi toplulaştırma projesinin uygulanmasını kolaylaştıracak ve arazi toplulaştırma projelerinin getirilerinden maksimum şekilde faydalanılmasını sağlayacaktır. Kötü yapılmış bir blok dağıtımı ise arazi sahiplerinin projeyi kabullenmesini zorlaştıracağı gibi toplulaştırmanın kadastro yenilemesinden ileri gidememesine neden olacaktır.

Blok dağıtımı ülkemizde arazi sahiplerinden alınan tercihler doğrultusunda yapılmaktadır. Arazi sahiplerinden üç tercih alınmakta ve tüm arazi sahipleri ilk olarak birinci tercihlerine yerleștirilmeye çalışmaktadır. Böylece birinci tercihlerine yerleştirilemeyen arazi sahipleri ikinci ve üçüncü tercihlerine yerleştirilmesi sağlanmaktadır. Bu işlemde karar vericinin rolü çok büyüktür, karar verici yeterince deneyim sahibi değilse dağıtımda istenilen başarı yakalanamaz. Bunun yanında ulaşım mesafelerinin azaltılması, toplulaştırma oranın mümkün olduğunca yüksek olması gibi faktörler de göz önüne alınmalıdır. Blok dağıtımının bir diğer zorluğu ise bloklarda dağıtımdan sonra fazlalık ya da eksikliklerin kalmasıdır.

Blok dağıtımında karar vericinin etkisini ortadan kaldırıp, zamanı kısaltmak ve arazi toplulaştırmasının amaçlarına daha uygun dağıtımı gerçekleştirmek için bilimsel bir metotla dağıtım yapmak gerekmektedir. Bu konuda (Şişman, 2017) tarafından yapılan çalışmada arazi toplulaştırmada dağıtım işleminin ulaştırma problemi olarak ele alınıp yöneylem araştırma teknikleri ile dağıtım problemine çözüm aranmıştır. (Ayrancı, 2007) çalışmasında önerilen modelde de dağıtım ulaştırma modeli olarak ele alınmış ve maliyet katsayısı hesaplanırken ulaştırma katsayısı, arazi sahiplerinin tercihleri, parsellerin alanları oranı göz önüne alınmıştır. Modelin çiftçi tercihlerini yerine getirmedeki başarısı test edilmiş ve gerçek dağıtıma göre daha iyi olduğu görülmüștür.

Mekânsal karar destek sistemleri ve blok öncelikli model kullanarak yapılan (Uyan, 2011) çalışmada ise modelin sonuçları mülakat esaslı model ve blok öncelikli modelle karşılaştırılmıştır. Toplulaştırma oranı bakımından en başarılı model mekânsal karar destek sistemleri ile yapılan olduğu görülmüştür.

Esnek yapısı ve büyük arama uzayında hızlı sonuca ulaşması bakımından genetik algoritmada arazi toplulaştırmasında sıkça kullanılmaya başlanmıştır. (Akkus, M. A., Karagoz, O., ve Dulger, 0. 2012) tarafından yapılan çalışmada arazi toplulaştırması dağıtım işlemi genetik algoritma kullanılarak gerçekleştirilmiştir. $\mathrm{Bu}$ modelde işletmeler en büyük parsellerinin olduğu bloğa ve sabit tesisler bulundukları bloğa atanarak başlangıç çözümü elde edilir. Başlangıç çözümü genetik algoritma kullanılarak iyileştirilir burada amaç fonksiyonu bloklardaki fazlalık ve eksiklikleri minimum yapmaya yöneliktir. Başlangıç çözümünde blok doluluk oranı \%82 iken bu oran genetik algoritma ile \%99.7'ye çıkarılmıştır. Gerçek dağıtımda bu oran \%97'dir.

Yine (Çay, T., İnceyol, Y., ve Özbeyaz, A., 2015) çalışmalarında, otomatik blok dağıtımı için genetik algoritma kullanılmasını önermişlerdir. Bu modelde kısıtlar dikkate alınmış ve dağıtımın çiftçi tercihlerine göre gerçekleştirilmesi amaçlanmıştır. Modelde sabit tesisler ilk olarak bulundukları bloklara yerleștirilir ve dağıtım işlemi bu işlemden sonra gerçekleştirilir.

Ayrıca bulanık mantık tabanlı ve birtakım hibrit algoritmalar kullanılarak dağıtımdaki sorunların üstesinden gelmek amaçlanmıştır. (Çay ve İşcan, 2011) çalışmalarında arazi toplulaştırması dağıtım işlemi bulanık mantık kullanılarak yapılmıştır. Dağıtımda işletmelerin en büyük parsellerinin ve en büyük ikinci parsellerinin konumu, sabit tesisler, parsellerin dağılımı kriterleri göz önünde bulundurulmuştur. Bu modelde blok dengelemesine ihtiyaç vardır. Yapılan dağıtım blok öncelikli modelle parsel sayısı, ortalama parsel büyüklüğü, kişi bașına düşen ortalama parsel sayısı gibi ölçütlere göre karşılaştırılmış bulanık mantık tabanlı dağıtımın daha avantajlı olduğu anlaşılmıştır. Çiftçi tercihlerini sağlama açısından ise blok öncelikli modelin daha üstün olduğu görülmüștür. (Çay, T., Ertun, E., Haklı, H., ve UĞUZ, H. 2017) çalışmalarında ise arazi toplulaştırma çalışmalarının en çok zaman alan aşaması olan dağıtım için bulanık mantık ve genetik algoritma kullanan hibrit bir algoritma önermişlerdir. Bu çalışmada tercihlere göre başarı oranı \%76.61 olarak bulunmuș ve genetik algoritmanın dağıtımda kullanılabilir olduğu gösterilmiştir.

Yapılan bu çalışmaların bir çoğunda dağıtımdan sonra bloklarda fazlalık ya da eksiklikler meydana gelmekte ve bunlar manüel ya da bir algoritma yardımı ile düzeltilmekte bu da dağıtımı optimum dağıtımdan uzaklaştırmaktadır. 
Çeşitli amaç fonksiyonlarına göre en iyi blok dağıtımını bulma işlemi bir optimizasyon problemidir. Böyle düşünüldügünde blok dağıtımı, günümüzde yaygin olarak kullanılan sezgisel algoritmalardan biri olan genetik algoritma ile yapılabilir. Genetik algoritma çözümler kümesinin (popülasyonun) çeşitli evrimsel operatörler yardımı ile istenilen amaca en uygun hale gelecek șekilde evrilmesidir. Ayrica hemen hemen her optimizasyon problemine uygulanabilmektedir.

Bu çalş̧mada blok dağıtımı bir optimizasyon problemi olarak ele alınmıș ve optimizasyon işlemi genetik algoritma kullanılarak yapılmıştır. Genetik algoritmanın yapısı blok dengelemesi ihtiyacını ortadan kaldıracak şekilde probleme uyarlanmış ve tek bir amaca göre dağıtım gerçekleştirilmiștir. (İnceyol, 2014) tarafından yapılan çalışmada arazi toplulaştırması dağıtım işleminde genetik algoritma kullanılmakta ve dağıtım sonrası bir blok dengelemesine ihtiyaç duyulmaktadır. Sonuçta gerçek dağıtım verilerinde toplulaştırma oranı $\% 22$ iken genetik algoritma ile yapılan dağıtımda bu oranı $\% 26$ blok öncelikli modelde ise \%44 olmuştur. İşletmelerin köy merkezlerine olan uzaklıkları bakımından karşılaştırılmasında ise mülakat esaslı yöntemde mesafelerin azaldığı genetik algoritma kullanılan yöntemde ise bu mesafelerin arttığı gözlenmiştir.

\section{YÖNTEM}

\subsection{Genetik Algoritma}

Genetik algoritma evrimsel süreçlerin taklit edildiği arama ve optimizasyon algoritmasıdır (Deb, 2001; Holland, 1992). Deterministik optimizasyon algoritmalarına göre; karmaşık işlemlerle uğraştırmayı gerektirmeme, hemen hemen her probleme uygulanabilme, büyük arama uzaylarında hızlı sonuca varma gibi avantajlara sahiptir (Çunkaș, 2006). Bu avantajlarından dolayı günümüzde yaygın olarak kullanılmaktadır.

Genetik algoritma evrimsel süreçlerde olduğu gibi seçilim, çaprazlama ve mutasyon sayesinde arama uzayı içerisinde en iyi sonuca ulaşır. Problemi tanımlamak için ise gen, kromozom (birey), popülasyon ve iterasyon (nesil) parametreleri kullanılır. Genler problemimizi ifade etmede kullanılan en küçük birimlerdir. Genlerin birleşimi ile kromozomlar (bireyler) meydana gelir ve kromozomların oluşturduğu kümeye ise popülasyon denir. Bu popülasyon seçilim, çaprazlama ve mutasyona tabi tutularak bir çok nesil boyunca arama uzayında amaca en uygun bireyin bulunması hedeflenir (Goldberg, 1989).

\subsection{Genetik Algoritma Uygulama Adımları}

Genetik algoritmada ilk olarak probleme uygun bir gen yapısı seçimi yapılır. Problemin yapısına göre genlerin yapısı da farklılık göstermektedir. İkili kodlama, permutasyon kodlama tam sayılı kodlama, gerçek değerli kodlama ve ağaç kodlama gibi gen çeşitleri vardır. Örneğin ikili kodlama daha küçük problemler için kullanılırken gerçek değerli kodlama büyük verileri işlemeyi gerektiren problemlerde kullanılır. Sıralamanın önemli olduğu problemlerde ise permutasyon kodlama kullanılmaktadır. Genlerden faydalanarak her biri problemin bir çözümü olan kromozomlar oluşturulur. Bu kromozomlar aynı zamanda birey olarak da ifade edilmektedir. Bireylerin yani çözümlerin bir araya gelmesi ile arama uzayında en iyi sonuca ulaşmamızı sağlayacak bir küme (popülasyon) oluşturulur.

Genetik algoritmanın genel uygulama prosedürü așağıda Şekil 1'de gösterildiği gibidir.

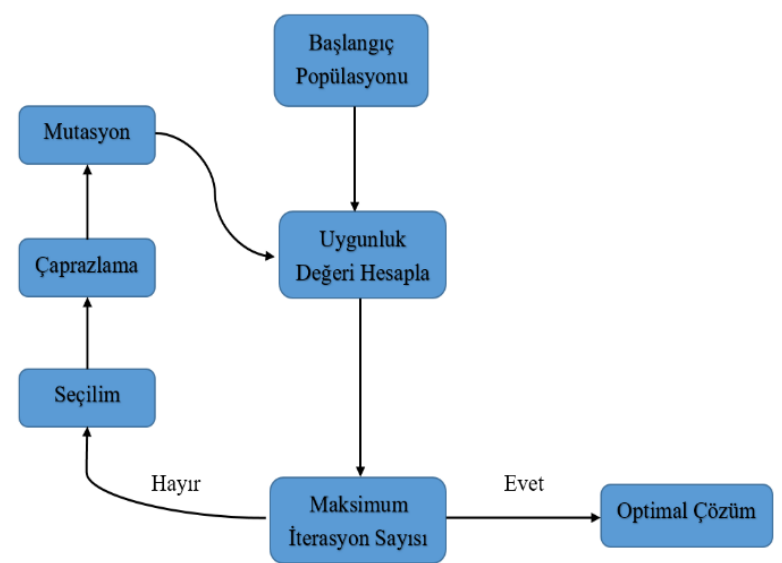

Şekil 1. Genetik Algoritma İşlem Adımları (Anonim, 2017)

Genetik algoritmanın işlem adımları şu şekildedir:

1- Problemin birden fazla çözümünden oluşan ilk popülasyon, problemin kısıtlarına uygun olarak rastgele üretilir. Popülasyon küçük tutulursa arama uzayında kisitlı bir bölgeden aramaya başlanacağından optimuma ulaşmak zaman alacaktır. Büyük popülasyon ise işlem yükünü arttıracak ve algoritmanın yavaşlamasına neden olacaktır.

2- Popülasyondaki her bireyin uygunluk değeri hesaplanır. Uygunluk değeri problemde belirtilen amaca ne kadar yaklaşıldığının bir ölçütüdür. Popülasyon hesaplanan bu uygunluk değerleri doğrultusunda evrilir.

3- Oluşturulan popülasyondan yeni bir nesil üretilmesi için popülasyon bir seçilim işlemine tabi tutulur. Bunun için çeşitli yöntemler mevcuttur en yaygın kullanılanları rulet çarkı, elitizm ve turnuva seçilim yöntemidir.

$\mathrm{Bu}$ çalışmada da kullanılan rulet çarkı yönteminde bireylerin uygunluk değerleri toplam uygunluk değerine bölünerek Tablo 1'de görüldüğü gibi olasılık değerleri hesaplanır. Daha sonra birikimli olasılık değerleri bulunur. Minimumu bulmayı hedefleyen problemlerde yukarıdaki işlemler amaç fonksiyonunun negatif işaretlisi alınarak yapılır (Karaboğa, 2017). 
Tablo 1. Bireylerin Uygunluk Değerleri ve Seçim Olasılıkları (Eroğlu, 2018)

\begin{tabular}{|c|c|c|c|}
\hline Kromozom & $\begin{array}{c}\text { Uygunluk } \\
\text { Değeri }\end{array}$ & Olasıllk & $\begin{array}{c}\text { Birikimli } \\
\text { Olasılık }\end{array}$ \\
\hline 1 & 7 & $\% 43.75$ & $\% 43.75$ \\
\hline 2 & 3 & $\% 18.75$ & $\% 62.50$ \\
\hline 3 & 1 & $\% 6.25$ & $\% 68.75$ \\
\hline 4 & 5 & $\% 31.25$ & $\% 100$ \\
\hline Toplam & 16 & $\% 100$ & \\
\hline
\end{tabular}

Seçim için popülasyon sayısına eşit, sıfır ile bir aralığında rassal sayılar olușturulur. Yukarıdaki Tablo 1'de de görüldüğü gibi uygunluk değeri daha iyi olan bireyleri temsil eden birikimli olasılık değeri aralığı daha geniştir. Bu da şu anlama gelmektedir, uygunluk değeri daha iyi olan bireylerin seçilme olasılıkları Şekil 2'de görüldüğü gibi daha yüksektir. Fakat düşük olasıllıkla da olsa uygunluk değeri küçük olan bireyler de seçilebilir (Karaboğa, 2017).

\section{Seçim Olasılıkları}

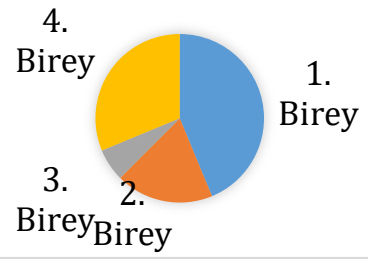

Şekil 2. Bireylerin Seçim Olasılıkları (Eroğlu, 2018)

4- Çaprazlama, seçilim işlemine tabi tutulan bireyler arasından rastgele iki birey seçilerek bu bireyler arasında yapılır. Popülasyondaki kaç bireyin çaprazlamaya tabi tutulup tutulmayacağı önceden belirlenen çaprazlama olasılığı parametresi ile bulunur. Çaprazlama için birçok farklı yöntem mevcuttur. Bunlardan en sık kullanılanları tek nokta çaprazlama, çift nokta çaprazlama, çok nokta çaprazlama ve uniform çaprazlamadır. En sık kullanılanı ise Şekil 3'te gösterilen tek nokta çaprazlama yöntemidir.

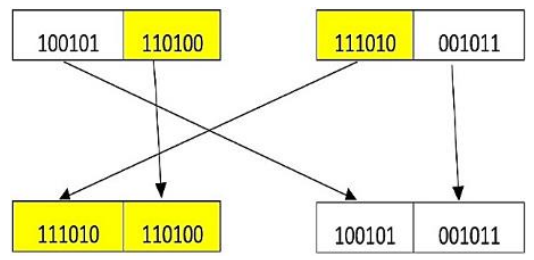

Şekil 3. Tek Nokta Çaprazlama (Eroğlu, 2018)

5- Mutasyon, seçilim ile oluşturulan popülasyondan rastgele seçilen bireylerin Şekil 4'teki gibi mutasyona tabi tutularak yeni bireyler elde edilmesidir. Mutasyona tabi tutulacak birey sayısı yine önceden tanımlanan mutasyon olasılığı ile belirlenir. Kromozom üzerinde hangi genin mutasyona uğrayacağı yine rastgele olarak seçilir.

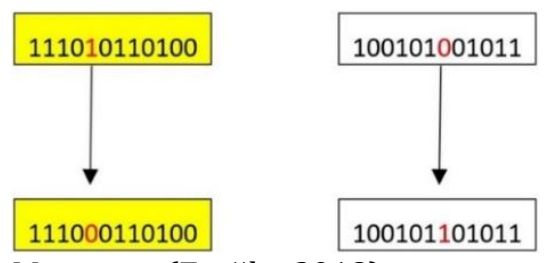

Şekil 4. Mutasyon (Eroğlu, 2018)

6- Son olarak seçilim, çaprazlama ve mutasyon operatörleri ile oluşturulan ara popülasyonlardan ilk popülasyon sayısı kadar birey seçilir. Bu seçilim ișlemi uygunluk değerlerine göre gerçekleștirilir. Elde edilen son popülasyon sırasıyla yine yukarıdaki işlemlere tabi tutulur.

Çaprazlama, iki bireyinde genetik bilgisini bir sonraki nesle aktaran bir operatördür. Çaprazlama ile oluşan birey ebeveyn bireylerden daha üstündür. Yani çaprazlama popülasyonumuzu giderek optimum noktaya yaklaştırır. Ancak mutasyon operatörü olmaksızın popülasyon lokal minimum ya da maksimuma takılacaktır. Mutasyon operatörü sayesinde popülasyondaki bireyler arama uzayının farklı noktalarına sıçrar ve böylelikle global optimuma ulaşmak mümkün olmaktadır. Mutasyonla üretilen kötü bireyler ise seçilim sayesinde popülasyondan kolaylıkla elenebilecektir. $\mathrm{Bu}$ ișlemlerden sonra popülasyonun ortalama uygunluk değeri istenilen noktaya geldiğinde iterasyon bitirilir. Ancak çoğu zaman bu istenilen uygunluk değeri bilinmediğinden iterasyon sayısı önceden tanımlanır. İstenilen iterasyon sayısına ulaşıldığında algoritma sonlandırılır (Çunkaş, 2006).

\subsection{Alt Başlıklar (Cambria, Kelime ilk Harfi Büyük, Kalın 10 Punto)}

İçerik 2 sütun halinde Cambria olarak 10 punto halinde yazılmalıdır.

İkinci düzey başlıklar numaralandırılmış ve sola dayall, 10 punto, ilk harfleri büyük, kalın olarak yazılmalıdır. Kendinden önceki paragraftan bir satır boșluk ile ayrılmalıdır. Biçimlendirmeyi bozmadan bu kısmı silip makale metnini yazabilirsiniz.

Metin içerisinde paragraflar arasında boşluk bırakılmamalıdır.

\subsection{Alt Başlıklar (Cambria, Kelime ilk Harfi Büyük, Kalın 10 Punto)}

İkinci düzey başlıklar numaralandırılmış ve sola dayalı, 10 punto, ilk harfleri büyük, kalın olarak yazılmalıdır. Kendinden önceki paragraftan bir satır boşluk ile ayrılmalıdır. Biçimlendirmeyi bozmadan bu kısmı silip makale metnini yazabilirsiniz.

\section{UYGULAMA}

Uygulama Şekil 5'te coğrafi konumu görülen Burdur ili Gölhisar İlçesinde yapılmakta olan 
Gölhisar Arazi Toplulaştırma ve TİGH Projesi Evciler Köyü 1. askı verileri kullanılarak gerçekleştirilmiştir.

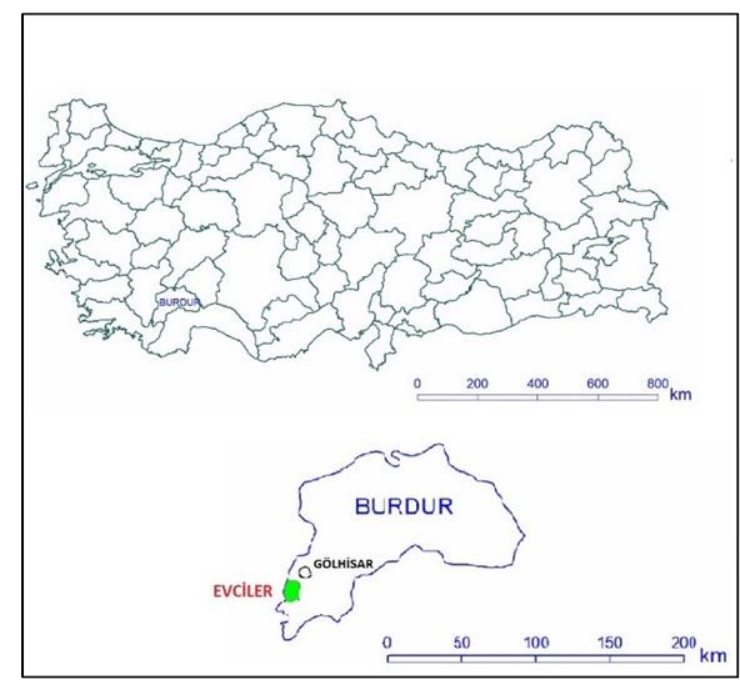

Şekil 5. Burdur Gölhisar Evciler Köyü Coğrafi Konum (Eroğlu, 2018)

Evciler Projesinde 101 işletme 12 blok ve 9 sabit tesis vardır. Projede dağıtım sırasında bazı işletmeler birlikte değerlendirilmiştir. Karşılaştırma yapılabilmesi açısından bu uygulamada da işletmeler aynı şekilde değerlendirilmiş ve son durumda işletme sayısı 87 olarak kabul edilmiştir. Yani dağıtım gerçekte olduğu gibi 87 işletme üzerinden gerçekleştirilmiştir. Böylelikle işletmelerin birbirleri ile hisselendirilmesinde bir değişiklik olmamıştır. Uygulamada sadece dağıtım yapılmış dağıtımdan sonra parselasyon planı yapılmamıștır. Projede toplam kadastro parsel alanı 49.61 hektardır.

İlk olarak dağıtım işleminin kolay yapılabilmesi için blok ve kadastro parsel alanları 1. derece alanlara dönüştürülür. Sabit tesislerin bulundukları bloklara ataması yapılır ve bu alanlar blok ile kadastro parsel alanından çıkarılır.

Yapılan çalıșmada dağıtım ișlemi benzerlik gösterdiği dengeli ulaştırma modeli olarak ele alınmıştır. Amaç fonksiyonu ulaştırma maliyetleri minimum yapılacak şekilde seçilmiştir. $\mathrm{Bu}$ amaç fonksiyonunda kullanılan ulaştırma maliyeti katsayıları işletmelerin blokların merkezine uzaklıkları ile kadastro parsellerinin ișletmelere olan ağırlıklı ortalama mesafelerinin birlikte göz önüne alınması ile hesaplanmıştır. $\mathrm{Bu}$ sayede işletmeler kadastro parsellerinin ağırlık merkezlerinin yakın olduğu bir bloğa atanırken parsellere ulaşım mesafesinin de en aza indirilmesi amaçlanır. Uygulama Matlab ortamında geliştirilmiştir.

\subsection{Ulaştırma Maliyeti Hesabı}

Dağıtımda amaç fonksiyonu olarak ulaşım mesafelerini en aza indirmek seçilmiştir. Ancak bu mesafeleri en aza indirirken parsellerin eski konumlarının köy merkezine olan uzaklıkları da göz önüne alınmalındır. Böylelikle yeni parsellerin dağıtımda kadastro parsellerinin ağırlık merkezine en yakın bloklara verilmesi amaçlanır. Burada ulaştırma maliyeti katsayısı

$$
C_{i j}=s_{i j}+\sqrt{\frac{s_{i}}{s_{i j}}}
$$

denklemi ile hesaplanır. $C_{i j}$ : i ve j işletmeleri arasındaki mesafe faktörü, $\bar{S}_{i j}$ : i ve j işletme arasındaki düzeltilmiş mesafe faktörü, $S_{i}$ : Toplulaştırma öncesi $\mathrm{i}$ işletmesinin kadastro parsellerine olan düzeltilmiş ortalama mesafesi. $S_{i j}$ 'nin değeri

$$
S_{i j}=\sum_{k=1}^{m} D_{i k} K_{k}
$$

eşitliği ile hesaplanır. Burada $D_{i k}$ : Gerçek yol uzunluğu, $K_{k}$ : Yol düzeltme faktörü. $\bar{S}_{i}$ ise

$$
\overline{S_{i}}=\frac{\sum_{p=1}^{m} A_{p}\left(\sum_{k=1}^{m p} D_{p k} K_{k}\right)}{\sum_{p=1}^{m} A_{p}}
$$

eşitliği ile hesaplanır. $A_{p}$ : Parsel alanı, $D_{p k}$ : Gerçek yol uzunluğu, $K_{k}$ : Yol düzeltme faktörü, i: İşletme numarası, j: Blok numarası, p: Parsel numarası, n: i işletmesindeki parsel sayısı şeklinde amaç fonksiyonu katsayıları hesaplanır. Uygunluk değeri hesabında kullanılan amaç fonksiyonu ise

$$
Z_{\text {min }}=\sum_{i=1}^{m} \sum_{j=1}^{n} C_{i j} X_{i j}
$$

denklemi ile hesaplanır (Şişman, 1997).

\subsection{Dağıtım İçin Oluşturulan Genetik Algoritma Yapısı}

Toplulaştırmada da tıpkı dengeli ulaștırma problemlerinde olduğu gibi arz ve talep dengesi korunarak dağıtım işlemi yapılması gerekmektedir. $\mathrm{Bu}$ da demek oluyor ki dağıtım işlemi sonrasında bloklarda fazlalık ya da eksiklik oluşmamalıdır. Bunu sağlamak için bu çalışmada kromozomlar arz talep dengesini koruyacak şekilde oluşturulmuş ve bu dengeyi bozmayacak özel çaprazlama ile mutasyon operatörleri kullanılmıştır. Veriler çok büyük olduğundan gen yapısı gerçek değerli kodlama seçilmiş kromozom yapısı

$$
X_{h}=\left[\begin{array}{ccccc}
X_{11} & X_{12} & X_{13} & \cdots & X_{1 n} \\
& \vdots & & \ddots & \vdots \\
X_{m 1} & X_{m 2} & X_{m 3} & \cdots & X_{m n}
\end{array}\right]
$$


gibi matris şeklinde tanımlanmıştır. Tasarlanan modelde genler işletmelerin alanlarını ifade eder. Kromozomdaki her satır bir işletme, her sütun ise bir bloğa karşılık gelir. Her satırın toplamı o işletmenin toplam alanını verirken her sütunun toplamı ise ilgili bloğun alanını verir. $\mathrm{Bu}$ yapı sayesinde hangi işletmeden hangi bloğa ne kadar alan atandığı rahatlıkla anlaşılabilir (Eroğlu, 2018).

\subsection{1 İlk Popülasyonun Oluşturulması}

İșletme ve blok sayıları sırayla m ve n olmak üzere, bloklarda eksik ya da fazlalık oluşturmayacak şekilde dağıtım aşağıdaki adımlar takip edilerek gerçekleştirilir.

1. $\Pi=\{1,2,3 \ldots \mathrm{mn}\}$ dizisinden rastgele bir ' $\mathrm{k}$ ' elemanı seçilir.

2. Bu elemana karşılık gelen 'i' satır ve 'j' sütun değerleri

$$
\begin{gathered}
i=\left[1+\frac{k-1}{n}\right] \\
j=[1+(k-1) \bmod n]
\end{gathered}
$$

şeklinde hesaplanır.

3. $X_{i j}=\min \left\{t_{i}, S_{j}\right\}$ atamasını yapılır ( $t_{i}$ arz kısıtı , $S_{j}$ talep kisıtı).

4. $\quad t_{i}$ ve $S_{j}$ değerleri

$$
\begin{aligned}
t_{i} & =t_{i}-X_{i j} \\
S_{j} & =S_{j}-X_{i j}
\end{aligned}
$$

şeklinde güncellenir ve ' $\mathrm{k}$ ' elemanını $\Pi$ dizisinden çıkartılır. Bu işleme П dizisinde eleman kalmayana kadar devam edilir (Ho ve Ji, 2005; Vignaux ve Michalewicz, 1991).

\subsubsection{Seçim}

Seçim için rulet çarkı yöntemi kullanılır ve aşağıdaki gibi gerçekleştirilir.

1. Popülasyondaki her bireyin uygunluk değeri hesaplanır. Bireylerin uygunluk değerlerinden faydalanılarak popülasyonun toplam uygunluk değeri

$$
\begin{aligned}
& \text { eval }\left(X_{h}\right)=\sum_{i=1}^{m} \sum_{j=1}^{n} C_{i j} X_{i j} \\
& \mathrm{~F}=\sum_{h=1}^{p s i z e} \operatorname{eval}\left(X_{h}\right)
\end{aligned}
$$

denklemleri ile hesaplanır.

2. Kromozomların seçim olasılıkları

$$
\begin{aligned}
& p_{h}=\frac{F-\operatorname{eval}\left(X_{h}\right)}{F *(p \operatorname{size}-1)} \\
& h=1,2 \ldots \text { psize }
\end{aligned}
$$

ile hesaplanır.

3. Birikimli olasılık değerleri

$$
\begin{gathered}
q_{h}=\sum_{j=1}^{h} p_{j} \\
h=1,2 \ldots \text { psize }
\end{gathered}
$$

denklemi ile hesaplanır.

4. 0-1 arasında rastgele bir sayı üretilir.

5. Birikimli olasılık değeri üretilen rastgele sayıdan büyük olan ilk kromozom(birey) seçilir. Örneğin birikimli olasılık değerleri $q_{1}=0.155$, $q_{2}=0.324, q_{3}=0.486, q_{4}=0.865, q_{5}=1$ olan 5 kromozomumuz olsun. Üretilen rassal sayı 0.436 olsun. Burada seçilecek kromozom $X_{3}$ 'tür (Ho ve Ji, 2005).

\subsection{3 Çaprazlama}

Klasik çaprazlama operatörleri arz talep dengesini gözetmediği için burada arz talep dengesini koruyacak bir çaprazlama operatörü kullanılmıştır. $\mathrm{Bu}$ yöntemde çaprazlanacak kromozomlar toplanır ve ikiye bölünür. Böylelikle yeni oluşan yavru bireylerin çaprazlanan bireylerden daha iyi olması garantilenmiș olur ve arz talep dengesi korunur.

1. Seçim adımındaki gibi bir çift kromozom seçilir. Bu kromozomlar $X_{1}$ ve $X_{2}$ olsun.

2. Seçilen kromozomlar

$$
X_{1}^{\prime}=\left(X_{1}+X_{2}\right) / 2
$$

şeklinde toplanır ve ikiye bölünür.

3. Çaprazlama işlemi sonucunda yeni bireylerden oluşan bir ara popülasyon elde edilir (Ho ve Ji, 2005; Vignaux ve Michalewicz, 1991).

\subsubsection{Mutasyon}

Klasik mutasyon operatörleri yine arz talep dengesini bozacağından bu kısıtlara uygun bir mutasyon operatörü kullanılmıştır.

1. Seçim adımındaki prosedür takip edilerek mutasyona uğratılacak bireyler seçilir.

2. Bu bireyin iki satır ve sütunu rastgele seçilir. 3. Seçilen satır ve sütunun yerine yeni popülasyon üretme işlemindeki adımlar 1 den 5 e kadar uygulanır ve yeni genler üretilir. $\mathrm{Bu}$ genler yerlerine yazılır ve yeni bir birey elde edilmiş olur (Ho ve Ji, 2005; Vignaux ve Michalewicz, 1991).

\subsection{Dağıtım Planı İçin Oluşturulan Genetik Algoritma Prosedürü}

Algoritmada kullanılan popülasyon büyüklüğü, iterasyon sayısı, çaprazlama oranı, mutasyon oranı 
uygulamamızı optimum dağılıma en hızlı ulaştıracak şekilde seçilmelidir. Bu parametreler denemelerle bulunabilir. Algoritmanın optimumum değerleri bulabilmesi için yukarıda tanımlanan operatörler aşağıdaki prosedüre göre uygulanmalıdır.

1. Popülasyon büyüklüğü, iterasyon sayısı, çaprazlama ve mutasyon oranı parametreleri tanımlanır.

2. İlk popülasyon Bölüm 3.2.1'de belirtilen ișlem adımları kullanılarak olușturulur.

3. Her bireyin uygunluk değeri hesaplanır.

4. Bölüm 3.2.2'deki adımlar izlenerek çaprazlanacak ve mutasyona tabi tutulacak bireyler seçilir. Çaprazlama ve mutasyon sonucu iki ara popülasyon oluşturulur.

5. Ana popülasyon ve oluşturulan iki ara popülasyon bireyleri arasında elitist strateji ile ana popülasyondaki birey sayısı kadar birey seçilir. Oluşan bu yeni popülasyon yeni nesildir.

6. Algoritmanın optimuma yakınlaşıp yakınlaşmadığını kontrol için her iterasyonun en iyi bireyi belirlenir. Bu işlemler iterasyon sayısı kadar tekrar eder (Ho ve Ji, 2005).

\section{BULGULAR}

Yapılan uygulamada dağıtım işleminde amaç ulaştırma maliyetlerini en aza indirirken en az sayıda parsel oluşturmaktır. Program İ7 $6700 \mathrm{HQ} 3.5 \mathrm{Ghz}$ işlemci, 16gb ram'e ve Nvida GTX 950M 4gb ekran kartına sahip bilgisayarda çalıştırılmıştır. Uygulama farklı iterasyon sayıları ve farklı çaprazlama, mutasyon parametreleri ile tekrarlanmış optimuma ulaşma süreleri gözlemlenmiştir. Ne kadar sürede optimuma ulaşıldığı ve diğer parametreler aşağıdaki Tablo 2 ve Tablo 3'te gösterilmiştir. İlk olarak genetik algoritma parametreleri; popülasyon sayısı 50 , çaprazlama oranı $\% 92$, mutasyon oranı $\% 10$ olarak seçilmiştir.

Tablo 2. Mutasyon oranı \%10 seçilerek yapılan dağıtım (Eroğlu, 2018)

\begin{tabular}{|l|l|l|l|}
\hline $\begin{array}{l}\text { İterasyon } \\
\text { Sayısı }\end{array}$ & Uygunluk Değeri & $\begin{array}{l}\text { Oluşan } \\
\text { Parsel } \\
\text { Sayısı }\end{array}$ & $\begin{array}{l}\text { İşlem Zamanı } \\
(\mathrm{sn})\end{array}$ \\
\hline 100 & 749873793.807810 & 368 & 0.482510 \\
\hline 1000 & 749873339.317948 & 423 & 2.290909 \\
\hline 100000 & 749868741.853841 & 139 & 199.38769 \\
\hline $\mathbf{5 0 0 0 0 0}$ & $\mathbf{7 4 9 8 6 8 7 1 8 . 9 6 2 4 8 9}$ & $\mathbf{1 0 8}$ & $\mathbf{9 0 1 . 5 0 2 9 3 0}$ \\
\hline
\end{tabular}

Daha sonra uygulama popülasyon sayısı 50, çaprazlama oranı \%92, mutasyon oranı \%90 yapılarak tekrar çalıştırılmıştır.

Her iki durumda da iterasyon sayısı artııça parsel sayısı ve ulaştırma maliyetleri yönünden daha iyi dağıtıma yaklaşıldığı görülmektedir. Ancak mutasyon oranını ve iterasyon sayısını arttırmak işlem zamanını olumsuz yönde etkilemektedir.
Tablo 3. Mutasyon oranı $\% 90$ seçilerek yapılan dağıtım (Eroğlu, 2018).

\begin{tabular}{|l|l|l|l|}
\hline $\begin{array}{c}\text { İterasyon } \\
\text { Sayısı }\end{array}$ & Uygunluk Değeri & $\begin{array}{l}\text { Oluşan } \\
\text { Parsel } \\
\text { Sayısı }\end{array}$ & $\begin{array}{l}\text { İşlem Zamanı } \\
(\mathrm{sn})\end{array}$ \\
\hline 100 & 749873607.951052 & 114 & 0.549255 \\
\hline 1000 & 749870129.058685 & 183 & 2.998468 \\
\hline 100000 & 749868718.817817 & 106 & 252.5272 \\
\hline $\mathbf{5 0 0 0 0 0}$ & $\mathbf{7 4 9 8 6 8 7 1 8 . 7 9 8 1 3 4}$ & $\mathbf{1 0 5}$ & $\mathbf{1 2 3 5 . 7 8 2 4 2 3}$ \\
\hline
\end{tabular}

Bloklara atanan alanlar ile blok alanları arasındaki fark bir blok dengelemesi yapılmaksızın Tablo 4'te gösterildiği gibi önemsenmeyecek düzeydedir. Çaprazlama ve mutasyon operatörleri de iterasyonlar sonucunda blok ve parseller arasındaki arz talep dengesini bozmamaktadır.

Tablo 4. İterasyon Sayllarına Göre Blok Doluluk Oraları (Eroğlu, 2018)

\begin{tabular}{|c|c|c|c|c|}
\hline $\begin{array}{c}\text { Itterasyon } \\
\text { Sayısı }\end{array}$ & 100 & 1000 & 100000 & 500000 \\
\hline 1. Blok & 0.000000 & 0.000000 & 0.000000 & 0.000000 \\
\hline 2. Blok & 0.000008 & 0.000003 & 0.000000 & 0.000000 \\
\hline 3. Blok & 0.000000 & 0.000146 & 0.000000 & 0.000000 \\
\hline 4. Blok & 0.000000 & 0.000002 & 0.000000 & 0.000000 \\
\hline 5. Blok & 0.000000 & 0.000001 & 0.000000 & 0.000000 \\
\hline 6. Blok & 0.000000 & 0.000001 & 0.000000 & 0.000000 \\
\hline 7. Blok & 0.000003 & 0.000000 & 0.000000 & 0.000000 \\
\hline 8. Blok & 0.000000 & 0.000063 & 0.000000 & 0.000000 \\
\hline 9. Blok & 0.005863 & 0.000117 & 0.000000 & 0.000000 \\
\hline 10. Blok & 0.000000 & 0.000017 & 0.000000 & 0.000000 \\
\hline 11. Blok & 0.000000 & 0.000089 & 0.000000 & 0.000000 \\
\hline 12. Blok & 0.009811 & 0.015245 & 0.015685 & 0.015685 \\
\hline
\end{tabular}

Kadastro durumu, gerçek veriler ve uygulama verileri karşılaştırıldığında uygulamada elde edilen sonuçların gerçek dağıtıma göre çok daha iyi olduğu Tablo 5'te görülmektedir.

Tablo 5. Gerçek Dağıtım ve Uygulama Verileri Karşılaștırması

\begin{tabular}{|l|l|l|l|}
\cline { 2 - 4 } \multicolumn{1}{c|}{} & $\begin{array}{l}\text { Kadastral } \\
\text { Durum }\end{array}$ & $\begin{array}{l}\text { Gerçek } \\
\text { Dağıtım } \\
\text { Verileri }\end{array}$ & $\begin{array}{l}\text { Genetik } \\
\text { Algoritma ile } \\
\text { Dağıtım }\end{array}$ \\
\hline $\begin{array}{l}\text { Toplam } \\
\text { Parsel Sayısı }\end{array}$ & 177 & 129 & $\mathbf{1 0 5}$ \\
\hline $\begin{array}{l}\text { Ortalama } \\
\text { Parsel } \\
\text { Büyüklüğü }\end{array}$ & $2.80 \mathrm{da}$ & $3.56 \mathrm{da}$ & $\mathbf{4 . 3 8} \mathbf{d a}$ \\
\hline $\begin{array}{l}\text { Ortalama } \\
\text { İșletme } \\
\text { Büyüklüğü }\end{array}$ & 4.91 & 4.55 & $\mathbf{4 . 5 5}$ \\
\hline
\end{tabular}

Mutasyon oranı \%10 ve \%90 olarak alındığında algoritmaların kaç iterasyonda optimum değere ulaştığı aşağıdaki şekillerde gösterilmiştir. Genelde mutasyon oranı çok düşük tutulması gerekir fakat bu uygulamada kromozomun büyüklüğüne oranla çok küçük bir mutasyon gerçekleştirildiği için bu oranın yüksek tutulmasının daha iyi sonuçlar verdiği görülmüştür. Mutasyon oranının iyi belirlenmemesi algoritmanın yerel minimuma ya da maksimuma takılmasına neden olacağından önemlidir. 
Aşağıdaki Şekil 6'te görüldüğü gibi mutasyon oranı \%10 alındığında optimuma yaklaşık 9000 iterasyonda ulașılmıștır. İkinci durumda Şekil 7'da görülüğü gibi mutasyon oranı $\% 90$ alındığında yaklaşı 2000 iterasyon sonunda optimuma ulaşılmıştır (Eroğlu, 2018)

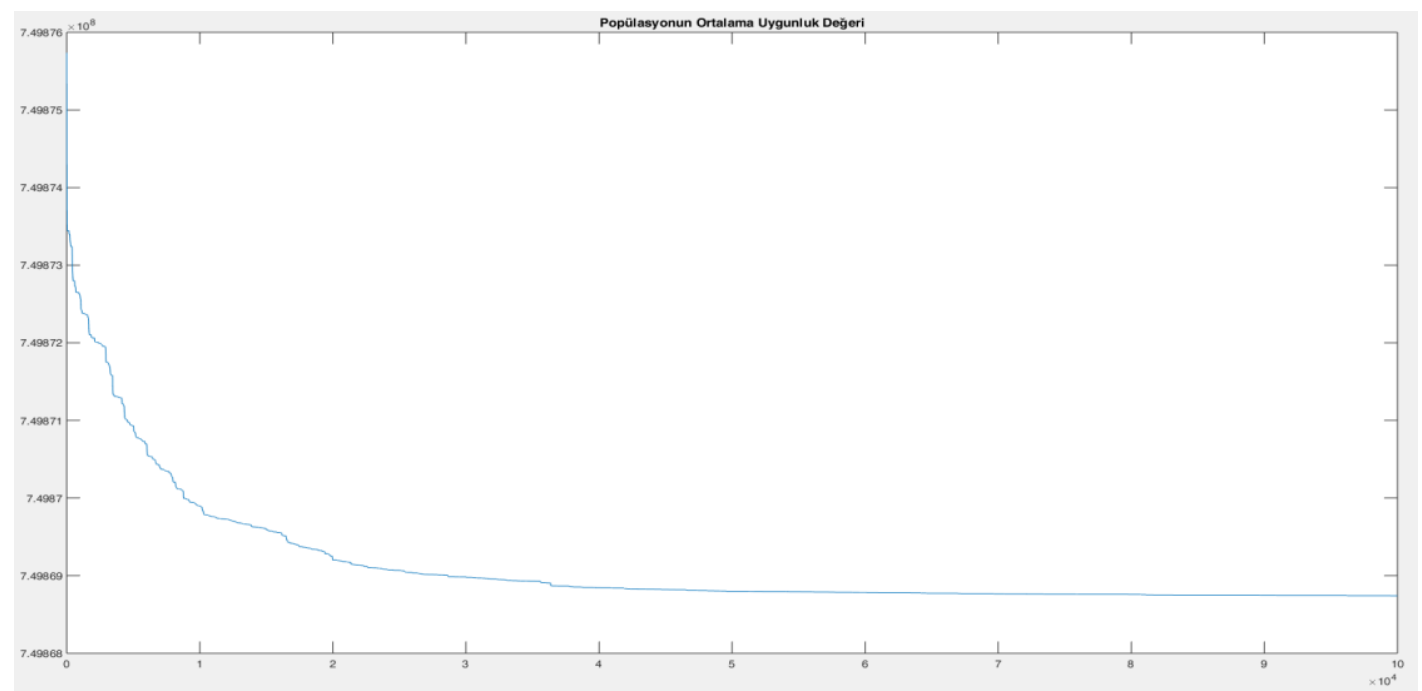

Şekil 6. Mutasyon Oranı \%10 Seçilen Popülasyonun Optimuma Ulaşma Grafiği (Eroğlu, 2018)

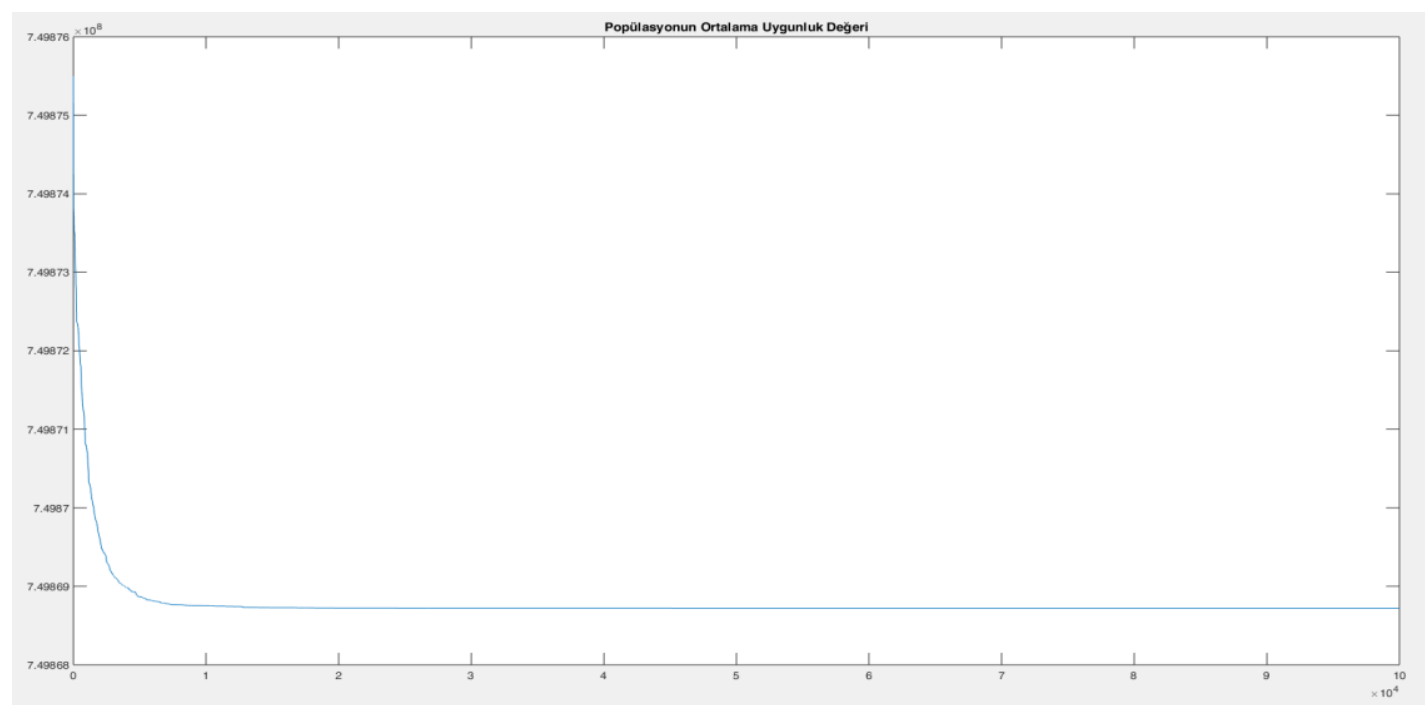

Şekil 7. Mutasyon Oranı \%90 Seçilen Popülasyonun Optimuma Ulaşma Grafiği (Eroğlu, 2018)

\section{SONUÇLAR ve TARTIŞMA}

Arazi toplulaştırmasında uygulamada karşılașılan zorluklar ve uygulama başarısının tamamen dağitım yapan kişinin tecrübe ve yeteneğine bağlı olması bilimsel bir metotlar dağıtım yapılması gerekliliğini açıkça ortaya koymaktadır.

Böylece istenilen amaca yönelik en doğru, optimum dağıtım elde edilebilecektir. Bu çalışmada bunun için genetik algoritma kullanan bir yaklaşım önerilmiş ve uygulama gerçekleştirilmiştir. Yapılan uygulamada dağıtım yaparken bloklarda eksiklik ya da fazlalıkların olușmasını engellemek ve aynı zamanda toplulaştırma oranını olabildiğince yüksek tutmak hedeflenmiștir. Kullanılan genetik algoritmada problemin doğasına özel modifikasyonlar yapılmış ve uygulama Matlab ortamında geliştirilmiştir.
Uygulama alanında kadastral durumda 177 parsel varken toplulaştırma çalışması ile bu 129 parsele düşürülmüştür. Genetik algoritma kullanılarak yapılan dağıtımda ise 105 yeni parsel oluşmuştur. Toplulaştırma oranı projede \%27 iken uygulama ile yapılan dağıtımda \%41'e yükselmiștir. Ayrıca amaçlandığı gibi bloklarda eksiklik ya da fazlalık oluşmamış ve bunun için ekstra bir blok dengeleme ișlemine ihtiyaç duyulmamıştır. Genetik algoritma ile yapılan dağıtımda parsel sayısı bakımından karşılaștırıldığında hem eski duruma göre hem de gerçek dağıtım verilerine göre iyileşme sağlandığı görülmüștür.

Dağıtımın doğası karmaşıktır. Bir faktörü örneğin sadece çiftçi tercihlerini göz önüne alarak dağıtım yapmak yanlıştır ve arazi toplulaştırmasından yeterince fayda sağlanamamasına neden olacaktır. Bu bakımdan 
arazi toplulaştırmasında ilk olarak yörenin de ihtiyaçları göz önüne alınarak hangi amaçlara göre dağıtım yaplacağı net olarak belirlenmelidir. Çiftçi tercihlerinin tutarlı olması için analitik hiyerarşi yöntemi kullanılmalı ve dağıtım için gerekli bilgi alt yapısı doğru bir şekilde oluşturulmalıdır.

Dağıtım işleminin yalnızca tek bir amaca göre örneğin çiftçilerin tercihleri göz önüne alınarak yapılması da doğru bir yaklaşım olmadı̆̆ından birden çok amacın birlikte değerlendirildiği bilimsel metotlar kullanılmalıdır.

Dağıtım işleminden sonra yapılacak parselasyon işlemi de arazi toplulaştırması açısından önemli bir adımdır. $\mathrm{Bu}$ aşamada da herhangi bir bilimsel yöntem kullanılmamaktadır. Toplulaştırmanın başarısını arttırmak için bu işlem de otomatik olarak bilimsel metotlarla yapılmalıdır.

\section{KAYNAKÇA}

Akkus, M. A., Karagoz, O., ve Dulger, O. 2012. Automated land reallotment using genetic algorithm. International Symposium on INnovations in Intelligent SysTems and Applications. 10.1109/INISTA.2012.6247018

Anonim. (2017). Genetik Algoritma. https://tr.wikiyy.com/wiki/Genetik_algoritma (Erişim Tarihi: 01 Haziran 2018)

Ayranci, Y. (2007). Re-Allocation Aspects in Land Consolidation: A New Model and its Application. Journal of Agronomy, 6:2, 270-277. doi: 10.3923/ja.2007.270.277

Çay, T., ve Iscan, F. (2011). Fuzzy expert system for land reallocation in land consolidation. Expert Systems with Applications, 38:9, 11055-11071. doi: 10.1016/j.eswa.2011.02.150

Çay, T., İnceyol, Y., ve Özbeyaz, A. (2015). A Preliminary Study for Design of Automatic Block Reallocation Algorithm with Genetic Algorithm Method in the Land Consolidation Projects. International Journal of Environmental, Chemical, Ecological, Geological and Geophysical Engineering, 9:8, 903-908.

Çay, T., Ertun, E., Haklı, H., ve UĞUZ, H. (2017). Arazi Toplulaştırmada Dağıtım İçin Yeni Yazılım Geliştirmesi Üzerine Bir Çalışma. 16. Türkiye Harita Bilimsel ve Teknik Kurultayı, 3-6 Mayıs 2017, Ankara.

Çunkaş, M. (2006). Genetik Algoritmalar ve Uygulamaları. Selçuk Üniversitesi Teknik Eğitim Fakültesi Ders Notları, Konya.

Deb, K. (2001). Multi-objective Optimization Using Evolutionary Algorithms. John Wiley \& Sons.
Eroğlu, H. (2018). Arazi Toplulaştırması Dağıtım İşleminde Yöneylem Araştırma Teknikleri ve Çok Amaçlı Genetik Algoritma Kullanılması. Yüksek Lisans Tezi, Ondokuz Mayıs Üniversitesi Fen Bilimleri Enstitüsü Harita Mühendisliği Anabilim Dalı, 117, Samsun.

Göçmen Dinçbilek, B. (2012). Arazi Toplulaştırmasının Toplu Yağmurlama Sulamada Sistem Planlaması ve Maliyetine Etkisi. Doktora Tezi, Ankara Üniversitesi Fen Bilimleri Enstitüsü Tarımsal Yapılar ve Sulama Anabilim Dalı, 188, Ankara.

Goldberg, D. E. 1989. Genetic Algorithms in Search, Optimization, and Machine Learning. AddisonWesley Professional, New York.

Ho, W., \& Ji, P. (2005). A genetic algorithm for the generalised transportation problem. International Journal of Computer Applications in Technology, 22(4), 190. https://doi.org/10.1504/IJCAT.2005.006959

Holland, J. H. (1992). Adaptation in Natural and Artificial Systems: An İntroductory Analysis with Applications to Biology, Control, and Artificial Intelligence. MIT Press. https://doi.org/10.1137/1018105

Karaboğa, D. (2017). Yapay Zeka Optimizasyon Algoritmaları (5. Baskı). Nobel Akademi Yayıncılık, 73-106, Ankara.

Polat, H., ve Manavbaşı, İ. (2012). Arazi Toplulaştırmasının Kırsal Alanda Yakıt Tüketimi Ve Karbondioksit Salınımına Etkisinin Belirlenmesi. Tarım Bilimleri Dergisi, 18(2), 157-165.

Şişman, A. (1997). Arazi Toplulaştırma Çalışmalarında Yöneylem Araştırması Uygulaması. Yüksek Lisans Tezi, Karadeniz Teknik Üniversitesi Fen Bilimleri Enstitüsü Harita Mühendisliği Anabilim Dalı, 78, Trabzon.

Uyan, M., ve Mevlüt. (2011). Arazi düzenlemesi çalışmalarında mekansal karar destek sistemleri kurulumu ve uygulaması. Doktora Tezi, Selçuk Üniversitesi Fen Bilimleri Enstitüsü Harita Mühendisliği Anabilim Dalı, 176, Konya.

Vignaux, G. A., ve Michalewicz, Z. (1991). A genetic algorithm for the linear transportation problem. IEEE Transactions on Systems, Man, and Cybernetics, 21(2), 445-452. https://doi.org/10.1109/21.87092 